\title{
Getting into the water: a prospective observational study of water immersion for labour and birth at a New Zealand District Health Board
}

\author{
Robyn M. Maude* (D) and Mikyung Kim
}

\section{Background}

Water immersion during labour and birth offers birthing women a means of non-pharmacological pain relief and a reduction in unnecessary and often routine intrapartum interventions [1]. Women who labour and birth in water are more likely to birth spontaneously and physiologically and experience fewer intrapartum interventions [2-4]. For the neonates of women who use water immersion during labour and birth, there are no additional risks compared to neonates born to women who do not use water immersion during labour and birth $[5,6]$.

In New Zealand, the use of water immersion during labour and birth is predominantly at home or in primary maternity facilities (midwife-led birthing units) for lowrisk women. Some secondary maternity units (for both uncomplicated and complicated pregnancies and births supported by multidisciplinary teams and access to operating theatres), and tertiary maternity units (for women with high-risk, complicated pregnancies, specialist services and level 3 neonatal intensive care unit) provide access to birth pools or baths for 'low risk' women to utilise during labour and birth [4]. For women without access to a primary birthing facility, the secondary or tertiary maternity unit may be her only option to use water immersion for labour and birth.

The New Zealand maternity system is an integrated system of primary, secondary and tertiary care that is free for most women. A Lead Maternity Carer (LMC) of

\footnotetext{
* Correspondence: RobynnMaude@vuwacnz
}

School of Nursing, Midwifery, and Health Practice, Faculty of Health, Victoria University of Wellington, PO Box 7625, Newtown, Wellington 6242, New Zealand

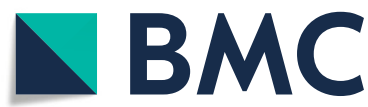

the woman's choice is responsible for care throughout pregnancy, labour and birth, and postnatally to 6 weeks. The LMC can be a midwife, a general practitioner (family physician) with a diploma in obstetrics or a private obstetrician (who can charge a fee for service). The majority (93.6\%) of pregnant women in New Zealand choose a case-loading community-based LMC midwife who provides continuity-of-care in the woman's home, a midwife-led unit, or a secondary or tertiary hospital [7]. If the maternity care becomes complicated, the caseloading community-based LMC midwife will refer the woman to the obstetric specialist team at a secondary or tertiary hospital. The obstetric specialist team will work with the hospital-employed midwives (also known as core midwives) (50.7\% of the midwifery workforce) [8], either to support the case-loading community-based LMC midwife to continue to provide care or to provide the woman's care following transfer of care.

There is a dearth of data available from secondary and tertiary maternity units where water immersion for labour and birth are offered, particularly in New Zealand. The lack of data is likely to be due to a lack of capacity of the information technology (IT) systems to record water immersion and water births. No complete national data is reporting on water immersion and water births across all maternity settings [7]. The only formal reporting of the use of water immersion for labour and birth comes from the Midwifery and Maternity Provider Organisation Ltd. (MMPO) from their midwife members [8]. In 2016, the most recently available published data, the percentage of water births was $10.8 \%$, although $26.8 \%$ of women in the report sample used water immersion during labour. Women who gave birth at a 
primary facility had a higher proportion of water births (34.8\%) than those birthing at secondary or tertiary facilities (7 and $2.9 \%$ respectively) [8]. There is a need to highlight the practice of and outcomes of water immersion and water birth in the New Zealand context. The research question guiding this study was: What are the characteristics and outcomes for women and their babies who used water immersion for labour and birth in maternity facilities in one New Zealand District Health Board?

\section{Methods}

This study aimed to describe the maternal characteristics, intrapartum events, interventions, and maternal and neonatal outcomes of women who used water immersion during labour and birth at one New Zealand District Health Board (DHB). This paper presents the results from a prospective observational study of women who used water immersion for labour and birth across the three maternity facilities in the DHB from February 2009 to March 2014.

\section{Setting}

The DHB maternity services include a tertiary-level maternity unit in a New Zealand city (average 3800 births per year) plus two midwife-led units (MLUs) (one at 30 mins and the other at $60 \mathrm{~min}$ away from the tertiary referral unit). At the tertiary maternity unit, there are 12 birth rooms each with the same design features, including a birth pool or bath, included in the new hospital design commissioned in 2009. The room size and layout differ slightly. Five rooms have a purpose-built birth pool while the remaining seven rooms have baths permanently installed in the corner of the room. The birth pools are round, $1200 \mathrm{~mm}$ in diameter and $650 \mathrm{~mm}$ deep. There is access around $66 \%$ of the pool, a shower, two handrails and steps into the pool. The baths are fivesided and are bound on two sides by a wall. The sides alongside the wall measure $1480 \mathrm{~mm}$, the two short slides measure $670 \mathrm{~mm}$ and the front access side measures $1080 \mathrm{~mm}$. The depth of the bathtub is $510 \mathrm{~mm}$. There is a hand-held mixer shower hose set plumbed in over the bath, four handrails, a sieve and thermometer and easy access to piped oxygen, suction and Entonox. At MLU 1 there is one bath measuring $1000 \mathrm{~mm}$ wide $\times$ $1840 \mathrm{~mm}$ long and $630 \mathrm{~mm}$ deep. The bath is in a separate room attached to two birth rooms. There is access around three sides of the bath, inner armrests and a headrest. All pools use a disposable liner. For comfort, a soft mat under the liner, and a floor mat are available for comfort for kneeling/laying on the floor around the bath. Equipment in the bathroom includes: a sieve, thermometer, a large mirror and an electric oil burner, portable oxygen, suction and Entonox are available. At
MLU 2 there is one bathroom with a purpose-built birth pool permanently installed towards the corner of the room adjacent to the only birth room. The birth pool is rectangular, measuring $1020 \mathrm{~mm}$ wide, $1350 \mathrm{~mm}$ long and $740 \mathrm{~mm}$ deep. There is a built-in seat which can also be used as a step to get in and out, with access around three sides of the pool.

\section{Participants}

Women who used the birth pool or bath during labour and birth across all three DHB maternity facilities, initiated at the time the new tertiary unit opened in February 2009 through to March 2014. Criteria for the use of water immersion for labour and birth usage, as outlined in the DHB guideline, as at least 37 weeks gestation, no adverse fetal or maternal factors in the pregnancy, an informed choice, established labour (judicious use for women with long latent labour is useful to promote relaxation) when there has been a diagnosis of labour dystocia (before using oxytocin). Ruptured membranes are not a contraindication for the use of the birth pool or bath.

\section{Data collection}

A paper-based data collection tool, included in the medical record of all women booked to birth at each of the three facilities, was adapted from the DHB water immersion guideline and the literature on water immersion. The form captured details of place of birth, type of caregiver and type of water facility as well as maternal characteristics (such as parity and gestation); and intrapartum events and interventions (such as labour onset, membrane rupture, vaginal examinations, pain relief). Maternal outcomes (such as length of labour, mode of birth, estimated blood loss, third stage technique, perineal or vaginal wall tear, labial tear, episiotomy, suturing) and neonatal outcomes (Apgar scores and NICU admission) were included (see supplementary file 1).

Lead Maternity Care (LMC) midwives or core (hospital employed) midwives were asked to complete the form for each woman who used water immersion during labour or birth. Midwives could also enter the presence of any risk factors from the current or previous pregnancies. Data were manually entered in Excel spreadsheet by the primary investigator and research assistant and transferred to SPSS Version 23 for analysis. Where data was unclear or missing, a review of other DHB data sources such as the DHB Patient Information Management System (PIMS) and clinical records of women and neonates (if admitted to Neonatal Intensive Care Unit (NICU) post-birth) occurred. The denominator of some variables differs given missing data. 


\section{Data analysis}

Descriptive statistics describe the characteristics of women who used water immersion during labour and birth and to describe the women and infants' birthing outcomes. Frequencies and percentages were calculated for categorical variables, mean and standard deviation for continuous variables.

\section{Ethics approval}

The New Zealand Health and Disability Ethics Committee (Approval number 15/CEN/55) provided research ethics approval.

\section{Results}

There were 1517 data collection forms completed for women who used a birth-pool or bath during labour and birth between February 2009 and March 2014: 1188 from the tertiary maternity unit and 329 from two midwifery-led units (164 from MLU 1 and 165 from MLU 2). There were approximately 19,628 births at the DHB facilities during the study period, indicating approximately $7.7 \%$ of women used water immersion for labour and birth. As the data collection was reliant on midwives manually completing the data collection form, we cannot be sure this number (1517) fully represented all women who used water for labour and birth during the data collection period.
Of the women for whom a data form was completed (1517) there were $584(38.5 \%)$ who had a water birth, 1275 (84\%) had a spontaneous vaginal birth, $242(16 \%)$ had assisted births or caesarean sections. Midwives attending women during labour and birth were community-based LMCs (92.7\%), core midwife/team (5.0\%) and medical LMC/core midwife (2.3\%).

There were 284 (18.7\%) data sheets that recorded risk factors for women who used water immersion for labour and birth during the data collection period. Examples of the risk factors recorded are in Fig. 1. The risk factors reported as 'others' (10.2\%) included oxytocin infusion, hydramnios, deflexed occipito-posterior position (OP), small for dates baby (SFD), maternal mental health, and haemophilia.

A little over half of the women in this study were nulliparous $(n=830,54.7 \%)$. Most women had a gestational age at labour onset of more than 38 weeks up to 42 weeks gestation (94.3\%). There were four women with a gestation of fewer than 36 weeks $(0.3 \%)$ and ten women whose gestation was more than 42 weeks $(0.7 \%)$ included in the analysis. Most (93.8\%) women's labour began spontaneously. The woman whose gestational age was less than 36 weeks and the three women whose gestational age were more than 42 weeks gestation had a water birth without any maternal and neonatal complications.

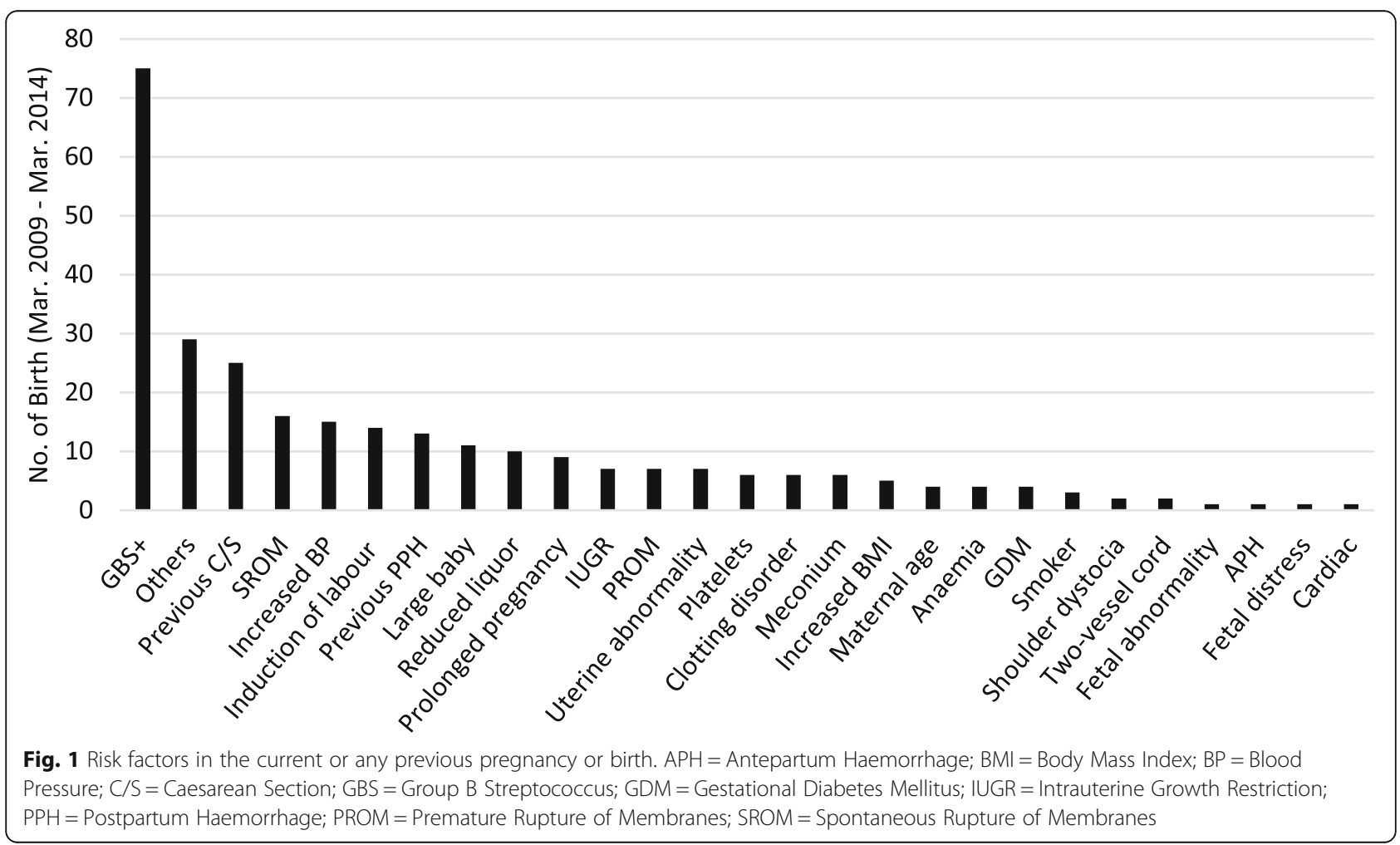


Nearly $56 \%$ of women used a birth pool and $44.3 \%$ used a bath. The mean cervical dilatation on entry to water was $5.6 \mathrm{~cm}$ (SD 2.1), and the mean number of contractions on entry to water in $10 \mathrm{~min}$ was 3.4 (SD $0.7)$. Water temperature on entry to a birth pool or bath ranged from $23^{\circ} \mathrm{C}$ to $44^{\circ} \mathrm{C}$ (mean $37.4^{\circ} \mathrm{C}$, SD1.3), and the exit temperature was between $24^{\circ} \mathrm{C}$ and $42{ }^{\circ} \mathrm{C}$ (mean $36.7^{\circ} \mathrm{C}$, SD 1.32).

Of the total 1517 women who used a birth pool or bath during labour, 677 women (44.6\%) left the birth pool or bath before birth. Just over $40 \%$ of women left the water at their request as they felt fatigued/unwell/ hot/cold. Others left due to a need for pharmacological pain relief $(10.9 \%)$, assessment $(9.5 \%)$, second stage (8.1\%), slow progress $(7.4 \%)$, fetal distress for cardiotocography (CTG, 6.1\%), change of position $(6.1 \%)$, and to use the toilet (3.2\%) (Fig. 2).

\section{Effects of water immersion for labour and birth on intrapartum events, interventions and maternal and neonatal outcomes}

From the 1517 women who used water immersion for labour and birth there were 584 (38.5\%) water births. More than half $(53.7 \%)$ of the water births occurred in multiparous women whereas only a quarter $(25.9 \%)$ of nulliparous had a water birth. Overall, the rate of spontaneous vaginal birth was $84 \%$ with $9.4 \%$ assisted deliveries and $6.5 \%$ caesarean sections. The proportion of assisted birth/CS was significantly higher in nulliparous
$(25.7 \%)$ than in multiparous $(4.2 \%) \quad(p=<0.001)$ (Table 1).

A quarter of the women had an artificial rupture of membranes (ARM). More than a third $(n=555,36.6 \%)$ of women in this study used pain relief after leaving the pool or bath (Table 1). The pharmacological pain relief commonly used were Inhalation/Entonox, Epidural, and Opioid. Alternative and complementary therapies used were transcutaneous nerve stimulation (TENS), acupuncture, acupressure, homeopathy, massage, and heatpack.

The mean duration of the first stage of labour was 330 mins (SD 238), the second stage of labour was 55 mins (SD 62) and the third stage of labour was 16 mins (SD 17) (Table 1).

Women generally preferred to adopt a semi-reclined (41.7\%) or a hands and knees position (15.8\%) for birth. Placental birth was actively managed in 917 (60.4\%) women whilst $594(39.2 \%)$ has a physiological third stage. Estimated blood loss below $500 \mathrm{mls}$ was recorded for $1322(87.1 \%)$ women, with 13 (0.9\% of women experiencing a post-partum haemorrhage of greater than $1500 \mathrm{mls}$ (seven following spontaneous vaginal birth and nine following operative birth).

Nearly $43 \%$ of women had an intact perineum following birth with first- and second-degree perineal tears being most common (25.7 and $27.4 \%$ respectively). Severe perineal trauma (3rd and 4th degree tears combined) occurred for 35 (2.3\%) women most during spontaneous vaginal birth, including the two 4th degree tears.

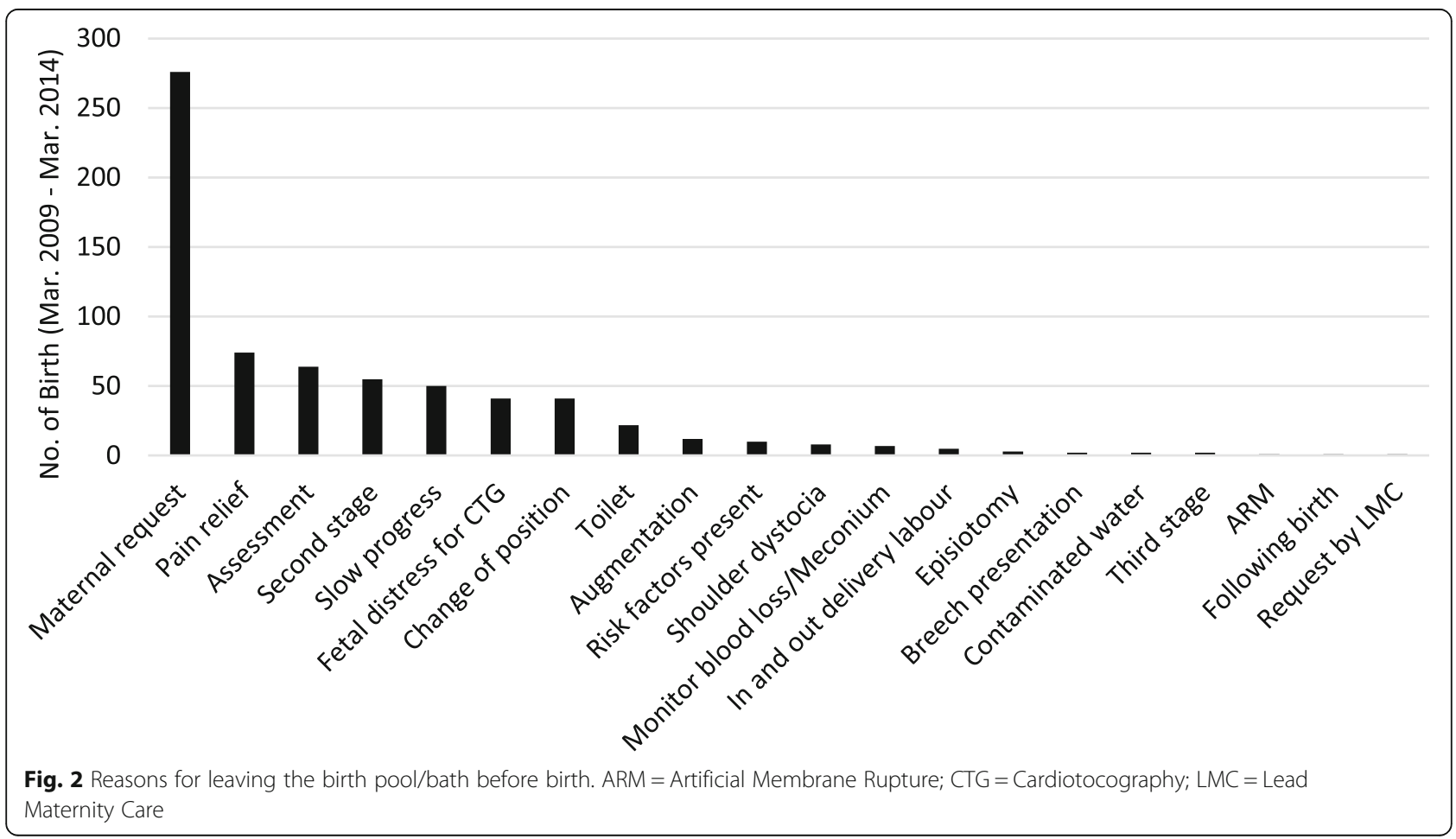


Table 1 Characteristics and outcomes for omen and babies who used water immersion for labour and birth

\begin{tabular}{|c|c|c|}
\hline \multicolumn{3}{|l|}{ Characteristics and outcomes } \\
\hline & Frequency & Percent \\
\hline \multicolumn{3}{|l|}{ Caregiver in labour } \\
\hline Self -employed Midwife & 1406 & 92.7 \\
\hline Core Midwife & 76 & 5.0 \\
\hline Dr. LMC/Core Midwife & 35 & 2.3 \\
\hline Total & 1517 & 100.0 \\
\hline
\end{tabular}

\section{Parity}

$$
\begin{aligned}
& \text { Nulliparous } \\
& \text { Multiparous } \\
& \text { Total }
\end{aligned}
$$$$
830
$$

Place of Birth

Tertiary Unit

Midwife-led Unit 1

Midwife-led Unit 2

165

Total

Gestation at start of labour

$$
\begin{aligned}
& <36 \text { weeks } \\
& 36-37^{6} \text { weeks } \\
& 38-39^{6} \text { weeks } \\
& 40-41^{6} \text { weeks } \\
& >42 \text { weeks } \\
& \text { Total }
\end{aligned}
$$

\section{Onset of Labour}

Spontaneous

Induced

Missing

Total

Membrane Rupture

$\begin{array}{ll}\text { Spontaneous } & 1128 \\ \text { Artificial } & 380 \\ \text { Intact } & 5 \\ \text { Missing } & 4 \\ \text { Total } & 1517\end{array}$

\section{Cervical dilatation on entry to water $(\mathrm{cm})$}

$$
\begin{aligned}
& 0 \\
& 1 \\
& 2 \\
& 3 \\
& 4 \\
& 5 \\
& 6
\end{aligned}
$$$$
4
$$$$
7
$$$$
8
$$

Table 1 Characteristics and outcomes for omen and babies who used water immersion for labour and birth (Continued)

\begin{tabular}{lll}
\hline Characteristics and outcomes & & \\
\hline & Frequency & Percent \\
\hline 9 & 61 & 4.0 \\
10 & 69 & 4.5 \\
Missing & 297 & 19.6 \\
Total & 1517 & 100.0 \\
Mean = 5.6cms (SD 2.1) & &
\end{tabular}

No. of contractions on entry to water in $10 \mathrm{mins}$

$\begin{array}{lll}1 & 3 & 0.2 \\ 2 & 83 & 5.5 \\ 3 & 678 & 44.7 \\ 4 & 511 & 33.7 \\ 5 & 44 & 2.9 \\ 6 & 4 & 0.3 \\ \text { Missing } & 194 & 12.8 \\ \text { Total } & 1517 & 100.0\end{array}$

Mean $=3.4(S D$ 0.7)

Water Temperature on entry to Pool $\left({ }^{\circ} \mathrm{C}\right)$

$\begin{array}{lll}\text { Below } 35 \text { degrees } & 18 & 1.2 \\ 35-35.9 & 14 & 0.9 \\ 36-36.9 & 222 & 14.6 \\ 37-37.9 & 482 & 31.8 \\ 38-38.9 & 346 & 22.8 \\ 39-39.9 & 117 & 7.7 \\ \text { Over } 40 \text { degrees } & 41 & 2.7 \\ \text { Missing } & 277 & 18.3 \\ \text { Total } & 1517 & 100.0\end{array}$

Mean $=37.4($ SD 1.3)

Pain Relief before entry to water

$\begin{array}{lll}\text { Yes } & 584 & 38.5 \\ \text { No } & 933 & 61.5 \\ \text { Total } & 1517 & 100.0\end{array}$

Pain Relief after leaving the pool

$\begin{array}{lll}\text { Yes } & 555 & 36.6 \\ \text { No } & 962 & 63.4 \\ \text { Total } & 1517 & 100.0\end{array}$

Number of Vaginal Examinations

$\begin{array}{lll}\text { None } & 1160 & 76.5 \\ 1 & 280 & 18.5 \\ 2 & 65 & 4.3 \\ 3+ & 9 & 0.6 \\ \text { Missing } & 3 & 0.2 \\ \text { Total } & 1517 & 100.0\end{array}$


Table 1 Characteristics and outcomes for omen and babies who used water immersion for labour and birth (Continued)

\begin{tabular}{lll}
\hline Characteristics and outcomes & & \\
\hline & Frequency & Percent
\end{tabular}

Length of 1 st stage of labour (mins)

Mean $=330($ SD 238)

Length of 2nd stage of labour (mins)

Mean $=55($ SD 62)

Length of 3rd stage of labour (mins)

Mean $=16(S D$ 17)

\section{Mode of Birth}

$\begin{array}{ll}\text { SVD OA } & 1250 \\ \text { SVD OP } & 25 \\ \text { Assisted delivery } & 143 \\ \text { CS } & 99 \\ \text { Total } & 1517\end{array}$

\section{Birth underwater}

Yes

No

Total

Position of mother at time of birth

$\begin{array}{ll}\text { Sitting } & 25 \\ \text { Kneeling } & 133 \\ \text { Standing } & 39 \\ \text { Hands and Knees } & 239 \\ \text { Lateral } & 34 \\ \text { Semi-reclined } & 632 \\ \text { Lithotomy } & 182 \\ \text { Squatting } & 83 \\ \text { Lying flat } & 122 \\ \text { Floating } & 2 \\ \text { Others } & 2 \\ \text { Missing } & 24 \\ \text { Total } & 1517\end{array}$

Third stage management

$\begin{array}{ll}\text { Active } & 917 \\ \text { Physiological } & 594 \\ \text { Both } & 6 \\ \text { Total } & 151\end{array}$

\section{Estimated blood loss}

0-499

500-999

1000-1499

$>1500$

Missing

Total

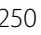

43

517
Table 1 Characteristics and outcomes for omen and babies who used water immersion for labour and birth (Continued)

\begin{tabular}{|c|c|c|}
\hline \multicolumn{3}{|c|}{ Characteristics and outcomes } \\
\hline & Frequency & Percent \\
\hline \multicolumn{3}{|c|}{ Perineal and/or vaginal wall tear } \\
\hline No & 648 & 42.7 \\
\hline Yes 1st degree & 390 & 25.7 \\
\hline Yes 2nd degree & 415 & 27.4 \\
\hline Yes 3rd degree & 33 & 2.2 \\
\hline Yes 4th degree & 2 & 0.1 \\
\hline Yes Graze & 20 & 1.3 \\
\hline Missing & 9 & 0.6 \\
\hline Total & 1517 & 100.0 \\
\hline \multicolumn{3}{|l|}{ Episiotomy } \\
\hline Yes & 213 & 14.0 \\
\hline No & 1294 & 85.3 \\
\hline Missing & 10 & 0.7 \\
\hline Total & 1517 & 100.0 \\
\hline \multicolumn{3}{|c|}{ Suturing of Tear/Episiotomy } \\
\hline Yes & 720 & 47.5 \\
\hline No & 784 & 51.7 \\
\hline Missing & 13 & 0.9 \\
\hline Total & 1517 & 100.0 \\
\hline \multicolumn{3}{|c|}{ Apgar score at $1 \mathrm{~min}$} \\
\hline$<7$ & 90 & 5.9 \\
\hline$\geq 7$ & 1421 & 93.7 \\
\hline Missing & 6 & 0.4 \\
\hline Total & 1517 & 100.0 \\
\hline \multicolumn{3}{|c|}{ Apgar score at 5 mins } \\
\hline$>7$ & 11 & 0.7 \\
\hline$\geq 7$ & 1499 & 98.8 \\
\hline Missing & 7 & 0.5 \\
\hline Total & 1517 & 100.0 \\
\hline \multicolumn{3}{|c|}{ Apgar score at 10 mins } \\
\hline$<7$ & 4 & 0.3 \\
\hline$\geq 7$ & 1038 & 68.4 \\
\hline Missing & 475 & 31.3 \\
\hline Total & 1517 & 100.0 \\
\hline \multicolumn{3}{|l|}{ Admission to NICU } \\
\hline Yes & 37 & 2.4 \\
\hline No & 1474 & 97.2 \\
\hline Missing & 6 & 0.4 \\
\hline Total & 1517 & 100.0 \\
\hline
\end{tabular}

Most neonates had an Apgar score greater than or equal to seven at both $1 \mathrm{~min}$ and $5 \mathrm{~min}$ post-birth (93.7 and $98.8 \%$ respectively). Only 37 (2.4\% of neonates 
required admission to NICU following birth. The reasons for NICU admission were recorded as low Apgar scores following shoulder dystocia, non-breathing, grunting, flat baby, respiratory problems, and meconium aspiration. There were no neonatal deaths (Table 1).

\section{Effect of birthplace at labour and birth on intrapartum events, interventions and maternal and neonatal outcomes}

The tertiary maternity unit was the most common planned birthplace for the women in this study at $78 \%$. More than half of nulliparous women ( $n=704,59 \%)$ chose the tertiary maternity unit for their birthplace over MLU 1 and MLU $2(n=67,41 \%$ and $n=59,36 \%$ respectively), whereas more multiparous women chose MLU 1 and MLU 2 ( $n=97,59 \%$ and $n=106,64 \%$ respectively) over the tertiary maternity unit $(n=484,41 \%)$. Midwiferyled units were more likely to adopt water birth than at the tertiary unit: approximately two-thirds of women who used water immersion during labour, both in MLU 1 and MLU 2, had a water birth $(n=106,65 \%$ and $n=108,65 \%$ respectively) however less than a third of women using water immersion at the tertiary maternity unit had a water birth $(n=370,31 \%)$ (Table 2$)$.

As expected, all births in the midwife-led units were Spontaneous Vaginal Births (SVB). The gestational age at start of labour was similar across all settings. The use of pain relief during labour differed by place of birth: before entry to the pool/bath 493 (41\%) of women in a tertiary maternity unit used pharmacological pain relief, whereas women in the midwife-led units used less (33 and $22 \%$ respectively) (Table 2 ).

In keeping with the strong association between water birth and physiological third stage of labour, 63\% $(n=$ 103) of women had a physiological third stage of labour at MLU 1 and $50 \%(n=82)$ at MLU 2 . In the tertiary maternity unit $65 \%(n=775)$ of women had an actively managed third stage of labour even.

A second-degree perineal tear was most common across all birth places with $30 \%$ at the tertiary unit, and 20 and $15 \%$ at the two midwife-led units respectively. Episiotomy was rarely used at the midwife-led units. Women in the tertiary maternity unit, where the water birth rate was much lower than MLU 1 and MLU 2, showed higher numbers of episiotomy and suturing than women in the MLUs (Table 2).

The Apgar scores at 1, 5 and $10 \mathrm{~min}$ across all the birth places were most usually $\geq$ seven. Most neonates born to women who used water immersion for labour and birth did not require admission to NICU (98\%).

\section{Discussion}

This study described the maternal characteristics, intrapartum events, interventions, and maternal and neonatal outcomes of women who used water immersion during labour and birth at one New Zealand DHB during the period 2009-2014. The data revealed $84 \%$ of women who used water immersion for labour and birth across all three birth settings in this DHB had a spontaneous vaginal birth (Nulliparous 74.3\%, Multiparous 95.7\%). This finding is important when compared with the DHB statistics reported in their 2009 annual clinical report that showed $41.3 \%(1643 / 3975)$ of all women who went to term, had a spontaneous labour then had a spontaneous vaginal birth (9). Of note, in this same report, only $34.5 \%(630 / 1826)$ of all primiparous women who went to term, had a spontaneous labour went on to have a spontaneous vaginal birth. The New Zealand national average for spontaneous vaginal birth was reported to be $65.2 \%$ in 2014 [9].

The New Zealand Clinical Indicators report outcomes for the 'standard primipara' across all DHBs and facilities [10]. They define the standard primipara as: women aged 20-34 years old at the time of giving birth who are giving birth for the first time (parity $=0)$ at term $(37-41$ weeks' gestation) where the outcome of the birth is a singleton baby, the presentation is cephalic and there have been no recorded obstetric complications that are indications for specific obstetric interventions (p. 8). This definition is used in data analysis to identify a group of women who are 'low risk', and for whom interventions and outcomes should be similar across all birthing facilities and regions. The New Zealand Clinical Indicators report a decrease in the proportion of standard primiparae who had a spontaneous vaginal birth, and continued variation between regions during the period 2009-2014, the same period as the data collected in this study.

The rate of water immersion for labour and birth was very small overall. Despite the availability of a bath or birth pool in every birthing room at the tertiary unit, approximately $7.7 \%$ of women used this during labour and birth. The finding that more women have a water birth in the MLUs than at the tertiary unit is likely to be influenced by the philosophy of LMC led community-based care. A midwifery-led continuity of care model in New Zealand means midwives can support women to birth at home, primary birthing units or in the hospital [11]. Most women birthing at the tertiary maternity unit in this study also had a community-based LMC (many of whom also practice at the MLUs) or core midwife providing their intrapartum care. Despite this, the rates of water immersion for labour and birth in the tertiary maternity unit are less than half the rates in the MLU. An explanation for the lower rate of water immersion for labour and birth in the tertiary maternity unit warrants review of the environment and culture of the tertiary maternity unit, which is geared more towards the needs 
Table 2 Characteristics and outcomes for women and babies who used water immersion for labour and birth by place of birth Characteristics and outcomes by place of birth

\begin{tabular}{|c|c|c|c|c|}
\hline & Tertiary maternity unit & Midwife-led unit 1 & Midwife-led unit 2 & Tota \\
\hline \multicolumn{5}{|l|}{ Caregiver in labour } \\
\hline Self-employed Midwife & 1077 & 164 & 165 & 1406 \\
\hline Core Midwife & 76 & 0 & 0 & 76 \\
\hline Dr. LMC/Core Midwife & 35 & 0 & 0 & 35 \\
\hline Total & 1188 & 164 & 165 & 1517 \\
\hline \multicolumn{5}{|l|}{ Parity } \\
\hline Nulliparous & 704 & 67 & 59 & 830 \\
\hline Multiparous & 484 & 97 & 106 & 687 \\
\hline Total & 1188 & 164 & 165 & 151 \\
\hline
\end{tabular}

\section{Gestation at start of labour}

$$
\begin{aligned}
& <36 \text { weeks } \\
& \text { 36-376 weeks } \\
& \text { 38-396 weeks } \\
& \text { 40-416 weeks } \\
& >42 \text { weeks } \\
& \text { Total }
\end{aligned}
$$$$
4
$$

Onset of Labour

\section{Spontaneous \\ Induced}

Total

Membrane Rupture

$$
\text { Spontaneous }
$$

Artificial

Intact

Total

Pain Relief before entry to water

Yes

No

Pain Relief after leaving the pool

Yes

No

685

Total

Length of 1st stage of labour (mins)

Mean (SD)

$352(249)$

Length of 2 nd stage of labour (mins) Mean (SD)

Length of 3rd stage of labour (mins)

Mean (SD)

Mode of Birth

SVD OA

SVD OP

\section{Tota \\ 406

234 (138)

22 (24)

19 (14)

164

1250

0 
Table 2 Characteristics and outcomes for women and babies who used water immersion for labour and birth by place of birth (Continued)

Characteristics and outcomes by place of birth

\begin{tabular}{lllll}
\hline & Tertiary maternity unit & Midwife-led unit 1 & Midwife-led unit 2 & Total \\
\hline CS & 99 & 0 & 0 & 99 \\
Total & 1188 & 164 & 165
\end{tabular}

Birth underwater

$\begin{array}{ll}\text { Yes } & 370 \\ \text { No } & 818 \\ \text { Total } & 1188\end{array}$

106

58

164

Position of mother at time of birth

$\begin{array}{ll}\text { Sitting } & 15 \\ \text { Kneeling } & 81 \\ \text { Standing } & 28 \\ \text { Hands and Knees } & 162 \\ \text { Lateral } & 21 \\ \text { Semi-reclined } & 517 \\ \text { Lithotomy } & 178 \\ \text { Squatting } & 44 \\ \text { Lying flat } & 117 \\ \text { Floating } & 1 \\ \text { Others } & 2\end{array}$

Total

Third stage management

Active

Physiological

\section{5}

409

Both

Total

4

1188

Estimated blood loss

$\begin{array}{ll}0-499 & 1011 \\ 500-999 & 131 \\ 1000-1499 & 24 \\ >1500 & 11 \\ \text { Total } & 1177\end{array}$

Perineal and/or vaginal wall tear

No

Yes 1st degree

492

281

Yes 2nd degree

358

Yes 3rd degree

31

Yes 4th degree

2

Yes Graze

Total

1180

\section{Episiotomy}

No

$15-3$

17

5

49

110

478

10

$17-1$

0

0

162

60

103

1

164

157

3

1

1

162

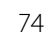

55

55

32

1

0

2

164

5

157

162

517

Total

517

584

933

1517

165

25

133

39

239

34

632

182

83

122

2

2

1493

165

917

594

6

1517

165

1322

141

26

13

1502

163

648

390

415

33

2

20

1508 
Table 2 Characteristics and outcomes for women and babies who used water immersion for labour and birth by place of birth (Continued)

\begin{tabular}{|c|c|c|c|c|}
\hline \multicolumn{5}{|c|}{ Characteristics and outcomes by place of birth } \\
\hline & Tertiary maternity unit & Midwife-led unit 1 & Midwife-led unit 2 & Total \\
\hline \multicolumn{5}{|c|}{ Suturing of Tear/Episiotomy } \\
\hline Yes & 613 & 56 & 51 & 720 \\
\hline No & 565 & 107 & 112 & 784 \\
\hline Total & 1178 & 163 & 163 & 1504 \\
\hline \multicolumn{5}{|c|}{ Apgar score at $1 \mathrm{~min}$} \\
\hline$<7$ & 79 & 8 & 3 & 90 \\
\hline$\geq 7$ & 1104 & 155 & 162 & 1421 \\
\hline Total & 1183 & 163 & 165 & 1511 \\
\hline \multicolumn{5}{|c|}{ Apgar score at 5 mins } \\
\hline$>7$ & 10 & 1 & 0 & 11 \\
\hline$\geq 7$ & 1172 & 162 & 165 & 1499 \\
\hline Total & 1182 & 163 & 165 & 1510 \\
\hline \multicolumn{5}{|c|}{ Apgar score at 10 mins } \\
\hline$<7$ & 0 & 0 & 0 & 0 \\
\hline$\geq 7$ & 859 & 116 & 67 & 1042 \\
\hline Total & 859 & 116 & 67 & 1042 \\
\hline \multicolumn{5}{|c|}{ Admission to NICU } \\
\hline Yes & 36 & 0 & 1 & 37 \\
\hline No & 1148 & 163 & 163 & 1474 \\
\hline Total & 1184 & 163 & 164 & 1511 \\
\hline
\end{tabular}

of the institution and influenced by a biomedical model of care, impacts on decision-making for women and midwives around timeframes, interventions and pain relief options, particularly the availability of epidural analgesia [1]. It is critical that these differences are discussed with women antenatally [1]. Support for healthy physiological birthing within the tertiary maternity should be a focus of education for both midwives and doctors [1] including the practice of supporting women to use water immersion for labour and birth.

The 2009 systematic review (Cluett and Burns, 2009) concluded that labouring in water reduces the need for pharmacological pain relief [11]. This study also found a reduction in the use of pain relief in the form of inhalation/Entonox, epidural, and opioid in the group of women who used water immersion for labour and birth. It is interesting to explore whether water immersion in and of itself influences a reduction in pain and the need for pain relief. An earlier qualitative study indicated that it was not necessary to give birth in the water to achieve the benefits of water immersion such as relaxation, increased ability to cope with pain, reduced fear and the to maintain control over the birth process [12].

In the literature, outcomes related to perineal trauma are mixed. Nutter and colleagues (2014) report that there is a decreased likelihood of severe perineal trauma (3rd and 4th-degree tears) associated with water birth [13]. In this study, there were only 35 (2\%) third, and fourth-degree tears which compares favourably with the number of third and fourth-degree tears reported at the DHB during 2015 (4.2\%) [14]. The rate of intact perineum was $43 \%$ which is significantly higher than the $17.9 \%$ rate reported for this DHB in 2015 [9].

Blood loss estimation is mainly subjective in most instances. The mean estimated blood loss over $1000 \mathrm{mls}$ low is low for all birth settings. While there were no other additional measures used in this study to determine the impact of blood loss such as haemoglobin estimation $[15,16]$, this finding is consistent with findings of Nutter and colleagues, 2014 [13].

As would be expected for this group of low-risk women, neonatal complications were few, with only 37 (2\%) of babies admitted to the NICU. The low rate of neonatal admission is in keeping with the findings of the 2016 systematic review of neonatal outcomes following water birth [17].

\section{Limitations}

The results presented are from a sample of women who gave birth in one DHB in New Zealand, and as 
such, the findings are only indicative of the practice in these settings. The results might not represent all women who used water immersion for labour and birth at the DHB during the time frame of this study. Anecdotally, during the study period, we were aware that not all midwives completed documentation all the time, but were unable to establish the extent of this, nor to enforce it. No data for maternal age or ethnicity were collected. A further limitation is the lack of a control group of low-risk women who met the eligibility criteria but did not use the bath or birth pool during labour. To reduce the proportion of missing data, a review of the PIMS and the clinical records occurred.

\section{Implications for practice}

The differences in outcomes by place of birth should prompt a discussion around what else is happening to impact the decisions of women and midwives. Focused education on water immersion for labour and birth for all midwives and doctors is warranted as well as antenatal education that provides evidence for the impact of place of birth and caregiver on outcomes for women and babies.

\section{Implications for research}

More research is required to explore factors impacting on women's decision-making around the use of water immersion for labour and birth as well as women's satisfaction. It would be beneficial to explore the factors influencing midwives to offer water immersion for labour and birth, and the barriers and facilitators to offering this service in the tertiary maternity environment.

\section{Conclusion}

Water immersion for labour and birth is a positive intervention that benefits well women with uncomplicated pregnancies. This study shows that water immersion for labour and birth in a midwife-led unit with a community-based lead maternity care midwife results in excellent outcomes for women and infants. Water immersion for labour and birth also provides an essential option for women who have a desire to have a spontaneous vaginal birth. The positive outcomes generated from water birthing indicate that this simple intervention may be a useful solution to address the high intervention rates in New Zealand's birthing population in tertiary and community settings. Midwives in both tertiary and community-based midwives should, therefore, campaign for improved accessibility to water immersion and water birth for women birthing in all birthing setting.

\section{Supplementary information}

Supplementary information accompanies this paper at https://doi.org/10. 1186/s12884-020-03007-6.

Additional file 1: Supplementary File 1. Water immersion outcome data collection sheet.

\begin{abstract}
Abbreviations
ARM: Artificial rupture of the membranes; BP: Blood pressure; C/S: Caesarean section; CTG: Cardiotocograph; DHB: District Health Board; HDEC: Health and Disability Ethics Committee; IOL: Induction of labour; IT: Information technology; LMC: Lead Maternity Carer; MLU: Midwifery led unit; MMPO: Midwifery and Maternity Provider Organisation; NICU: Neonatal Intensive Care Unit; OP: Occipito-anterior position; OP: Occipito-posterior position; PIMS: Patient information system; PPH: Postpartum haemorrhage; SD: Standard deviation; SFD: Small for dates; SROM: Spontaneous rupture of membranes; SVB: Spontaneous vaginal birth; TENS: Transcutaneous electrical nerve stimulator
\end{abstract}

\section{Acknowledgements}

Dr. Kathy Nelson for writing support and guidance and Dr. Lisa Woods for statistical advice.

\section{Authors' contributions}

RM conceived the idea and developed the outline for the study. MK entered the data into SPSS and developed an analysis plan and conducted an analysis with advice and supervision from RM. RM and MK drafted the manuscript. RM and MK were involved in the interpretation of data, review and revision of the draft manuscript and approval of the final version.

\section{Funding}

Small grants awarded by the Graduate School of Nursing, Midwifery and Health and the Faculty of Humanities and Social Sciences, Victoria University of Wellington. The funding bodies had no input into the design of the study, collection of data, analysis, interpretation of the data, nor the writing of the manuscript.

\section{Availability of data and materials}

The datasets used and/or analysed during the current study are available from the corresponding author on reasonable request.

\section{Ethics approval and consent to participate}

Research ethics approval from the New Zealand Health and Disability Ethics Committee (HDEC) on 29th June 2015 - application number 15/CEN/55. No participant consent required for audit is not required; however, locality assessment and approval from the study site occurred. No identifying features including names, addresses, dates of birth or NHI numbers were attached to the data once it is entered on to SPSS.

\section{Consent for publication}

Institutional consent for publication was granted by the District Health Board where the data was collected. No images or personal details of participants are used in the manuscript.

\section{Competing interests}

The authors declare that they do not have any financial or non-financial competing interests.

Received: 13 June 2018 Accepted: 11 May 2020

Published online: 20 May 2020

\section{References}

1. Plint E, Davis D. Sink or swim: water immersion for labour and birth in a tertiary maternity unit in Australia. Int J Childbirth. 2016;6:206-22.

2. Burns E, Boulton M, Cluett E, Cornelius V, Smith L. Characteristics, interventions, and outcomes of women who used a birthing pool: a prospective observational study. BIRTH. 2012;39:3.

3. Henderson J, Burns E, Regalia A, Casarico G, Boulton M, Smith L. Labouring women who used a birthing pool in obstetric units in Italy: a prospective observational study. BMC Pregnancy Childbirth. 2014;14:17. 
4. Lukasse M, Rowe R, Townend J, Knight M, Hollowell J. Immersion in water for pain relief and the risk of intrapartum transfer among low-risk nulliparous women: secondary analysis of the birthplace national prospective cohort study. BMC Pregnancy Childbirth. 2014;14:60.

5. Davies R, Davis $D$, Pearce $M$, Wong $N$. The effect of waterbirth on neonatal mortality and morbidity: a systematic review and meta-analysis. JBI Database Syst Rev Implementation Rep. 2015;13(10):180-231. https://doi. org/10.11124/jbisrir-2015-2105.

6. Bovbjerg M, Cheyney M, Everson C. Maternal and newborn outcomes following waterbirth: the midwives alliance of North America statistics project, 2004 to 2009 cohort. J Midwifery Womens Health. 2016;61:11-20. https://doi.org/10.1111/jmwh.12394.

7. Maude R, Caplice S. Using water for labour and birth. In: Pairman S, Pincombe J, Thorogood C, Tracy S, editors. Midwifery preparation for practice. 3rd ed. Sydney: Elsevier; 2015.

8. Daellenbach S, Gardner B, Dixon L, Guilliland K. Report on New Zealand MMPO midwives care activities and outcomes 2016. Christchurch: New Zealand College of Midwives; 2016.

9. Ministry of Health. Report on maternity 2015. Wellington: Ministry of Health; 2017.

10. Ministry of Health. New Zealand maternity clinical indicators 2015 Wellington: Ministry of Health; 2016.

11. Cluett E, Burns E. Cuthbert, A. Immersion in water in labour and birth. Cochrane Database Syst Rev. 2018;(5). Art. No.CD000111. https://doi.org/10. 1002/14651858.pub4.

12. Maude R, Foureur M. It's beyond water - stories of women's experience of using water for labour and birth. Women Birth. 2007;20(1):17-24.

13. Nutter E, Meyer S, Shaw-Battista J, Marowictz A. Waterbirth: an integrative analysis of peer-reviewed literature. J Midwifery Womens Health. 2014; 14(59):286-319.

14. Fisher $\mathrm{K}$, Elder R, Maude R, Fuge C, Thomson M. The women's health service annual clinical report 2009. (Name)DHB: city in NZ; 2010.

15. Geissbuehler V, Stein S, Eberhard J. Waterbirths compared with land births: an observational study of nine years. J Perinat Med. 2004;32:308-14.

16. Zanetti-Dallenbach R, Tschudin S, Zhong Y, Holzgreve W, Lapaire O, Hosli I. Maternal and neonatal infections and obstetrical outcomes in water birth. Eur J Obstet Gynecol Reprod Biol. 2007;134(1):37-43.

17. Taylor H, Kleine I, Bewley S, Locaides E, Sutcliffe A. Neonatal outcomes of waterbirth: a systematic review and meta-analysis. Arch Dis Child Fetal Neonatal Ed. 2016;101:F357-65.

\section{Publisher's Note}

Springer Nature remains neutral with regard to jurisdictional claims in published maps and institutional affiliations.

Ready to submit your research? Choose BMC and benefit from:

- fast, convenient online submission

- thorough peer review by experienced researchers in your field

- rapid publication on acceptance

- support for research data, including large and complex data types

- gold Open Access which fosters wider collaboration and increased citations

- maximum visibility for your research: over $100 \mathrm{M}$ website views per year

At $\mathrm{BMC}$, research is always in progress.

Learn more biomedcentral.com/submissions 